\title{
Investigation into informational compatibility of Building Information Modelling and Building Performance Analysis software solutions
}

\author{
S. Hyun, L. Marjanovic-Halburd \& R. Raslan \\ UCL Institute for Environmental Design and Engineering, \\ The Bartlett School of Environment, Energy and Resources, UK
}

\begin{abstract}
There are significant opportunities for Building Information Modelling (BIM) to address issues related to sustainable and energy efficient building design. While the potential benefits associated with the integration of BIM and BPA (Building Performance Analysis) have been recognised, its specifications and formats remain in their early infancy and often fail to live up to the promise of seamless interoperability at various stages of design process. This paper conducts a case study to investigate the interoperability between BIM and BPA tools, and discusses the limitations to suggest development of Information Delivery Manual (IDM) aiming to propose potential solutions for typical issues facing professionals in architecture, engineering and construction (AEC) industry.

Keywords: BIM (Building Information Modelling), BPA (Building Performance Analysis), LoD (Level of Detail/Development), IDM (Information Delivery Manual).
\end{abstract}

\section{Background}

Buildings can have extensive direct and indirect impacts on the environment throughout their life cycle. The building sector alone, contributes up to $19 \%$ of global annual Greenhouse Gas (GHG) emissions and consumes up to $32 \%$ of all global energy, and it will more than double in the next 50 years [1]. Therefore, if targets for GHG emissions reduction are to be met, it is clear that decision-makers must tackle emissions from the building sector [2]. 
Recent answers to this challenge call for an integrated, synergistic approach that considers all phases of the facility life cycle. This approach, called "sustainable building design", supports an increased commitment to "environmental stewardship and conservation, and results in an optimal balance of cost, environmental, societal, and human benefits while meeting the mission and function of the intended facility" [3].

According to the US Green Building Council [4], input from all key stakeholders and members of the design team is essential before schematic design begins, particularly since $70 \%$ of the decisions associated with environmental impacts are made during the first $10 \%$ of the design process. There are reasons to suggest that the best results in meeting increasingly aggressive goals for energy and carbon reduction are best achieved through collaborative processes [5, 6].

The Royal Institute of British Architects (RIBA) seeks to make an important contribution to this transformation of the construction sector by developing a new Plan of Work (PoW) that incorporates sustainable design principles, provides the infrastructure to support Building Information Modelling (BIM), and promotes integrated working between project team members [7]. BIM represents the latest incarnation of a logical progression from working in $2 \mathrm{D}$ and $3 \mathrm{D}$ but with all participants effectively going it alone to the exchange of information, and eventually moving to working in a shared digital environment [8]. There are significant opportunities for BIM tools to address issues related to sustainable building design. Data incorporated into a BIM can be used for Building Performance Analysis (BPA) to test, analyse, and improve the performance of a building, including aspects such as daylighting, energy efficiency and sustainable materials. As BIM continues to develop, technology providers will need to improve its ability to address the sustainable design and construction demands of the industry [9].

While the potential benefits associated with this interoperability have been recognised, BIM interoperability specifications and formats remain in their early infancy and often fail to live up to the promise of seamless interoperability and communication challenges faced by today's construction professionals [10]. Significant long-term challenges remain in addressing the different level of detail/developments (LoDs) required to support different construction activities including design, analysis, detailing, fabrication and coordination activities at different design stages. Furthermore, industry groups continue to strive to establish testing and certification of implementations of interoperability standards to ensure that rapid continued progress is made by software developers toward making data transfer reliable and routine [11].

This paper investigates the interoperability between BIM and BPA state of the art tools in the live project currently at RIBA Stage L. The main aim is to identify typical issues facing professionals in architectural and engineering companies and to propose potential solutions. Case study approach in general emphasises detailed contextual analysis of a limited number of events or conditions and their relationships, and is suitable to examine contemporary real-life situations and provide the basis for the application of ideas and extension of methods [12], and as such represents an adequate approach in achieving the objectives of this study. 


\section{BPA and BIM}

BPA is the use of computer-based simulations to access overall building energy performance and other characteristics of a building design. It allows for the analysis of various design considerations prior to the construction phase of a project. In this way, energy modelling can help optimise alternatives and allow the design team to prioritise investment in the strategies that will have the greatest effect on the building's energy use and occupant comfort [13].

Previously, many different BPA techniques have been applied to numerous studies and practical building projects in an attempt to predict future energy usage. A wide variety of BPA tools have been developed, improved, and utilised throughout the field of energy and built environment [14]. Among those, there are a number of whole building energy performance simulation tools that are widely used today for the various purposes of building design, performance analysis and validation, such as DOE-2, EnergyPlus, RIUSKA, eQuest, DesignBuilder, IESVE, EDSL TAS, Hevacomp and so on [15].

Although great advances have been made over the last few decades in BPA technologies and tools, limitations still exist. Research has shown that using BPA tools takes a considerable amount of time to properly input data correctly even for qualified practitioners [16]. Because of the length of time it typically takes to perform this type of simulation and analysis and deliver sought answers in the conventional ways, its results tend to lag in time behind the timing of design decision making [17]. Also, the conventional building energy performance analysis can be based on potentially arbitrary model definitions [7]. The resulting definition depends on energy modeller's point of view on modelling and understanding of the subject building, his or her knowledge and skill, experience, worldview, complexity of the building geometry of the subject building, complexity of the building itself, available resources, and more. It also sometimes results in over-prediction of energy savings in buildings due to the inaccuracy of tool itself, thus the analysis results can be unreliable in these cases; and the conventional process cannot qualify as means of testing and experimentation with virtual buildings regardless of the simulation tools used [18].

As a shared and necessarily up-to-date source of project information, the value of BIM and its data-handling power is best realised when it stretches from inception through design, delivery, handover, operation and eventual demolition, thereby also enabling comparable reusable data and feedback [19]. BPA using BIM has the potential to increase efficiency of the conventional process by leveraging building information that exists in the architectural or mechanical models created by the project design team. Also, by using BIM, the process of creating an energy model has the potential to become automated and formulaic, so that, at the very least, the geometry and other assumptions specified in the architectural model remain consistent across users and are not subject to interpretation or improper simplification [20].

According to the report by Lawrence Berkeley National Laboratory, a BIMbased building energy performance simulation has been reported that it demonstrated a $70 \%$ to $80 \%$ savings in time and effort compared to the traditional 
process [21]. This method was also capable of significantly reducing the time needed to pre-process, configure, execute, and post-process this design task while improving its consistency over conventional methods [22].

The architecture, engineering and construction (AEC) industry is now demanding to adopt BIM as a valuable sustainable design tool which enables an integrated practice methodology [6]. The BIM-based process is now possible for them to work together within a shared model in an improved coordination and organisation. This interaction is called Integrated Design Process (IDP) in which the purpose is to utilise a collaborative team effort to prepare design and construction documents that result in an optimised project system solution [23].

However, BIM tools limit interoperability for use in energy simulations without appropriate format and definition of LoDs [24, 25]. Currently, the Industry Foundation Class (IFC) and Green Building XML (gbXML) are two prevalent informational infrastructures in the AEC industry. Both IFC and XML create a common language to transfer BIM information between different BIM applications while maintaining the meaning of different pieces of information in the transfer. However, for a reliable data exchange, these definitions need to be implemented in software applications and thoroughly tested as they do not currently support all building information required for BPA.

\section{Case study findings}

\subsection{Overview of the case study building}

The case study building is an educational facility for youth training and experience days, graduate apprentice and staff training with some offices. The $3,000 \mathrm{~m}^{2}$ building is composed of a 3 storey linear building and it can accommodate maximum 500 occupancy. The building is seeking to achieve BREEAM Excellent level and to reduce carbon emissions by $35 \%$ by 2050 from 2008/9 baseline as identified in the client's own sustainability guidelines. Deciding on what material to use on a building is driven by client's low carbon construction strategies.

The client also has provided a BIM Execution Plan (BEP) for this building. It is produced by the facility management (FM) team of the client side as the on-site information library for the facilities in the campus is disjointed, incomplete and patchy restricting the use and availability of information and presenting problems for the on-going maintenance of assets. The BEP identifies who, when and how data is to be added to the models for data development, delivery and maintenance for all BIM work streams.

Autodesk Revit, one of the BIM authoring tools, has been used to model the case study building as required in the BEP provided by the client. The Revit model has been developed according to each design stage defined by RIBA Plan of Work (PoW) 2007 to be delivered to the client accordingly. The RIBA Stage K model is presented on the left hand side of Figure 1.

As the case study building aims to achieve a number of sustainability criteria, IES-VE, one of the building performance analysis tools, has been used for the energy modelling. The energy analyses have been conducted using IES-VE at the 


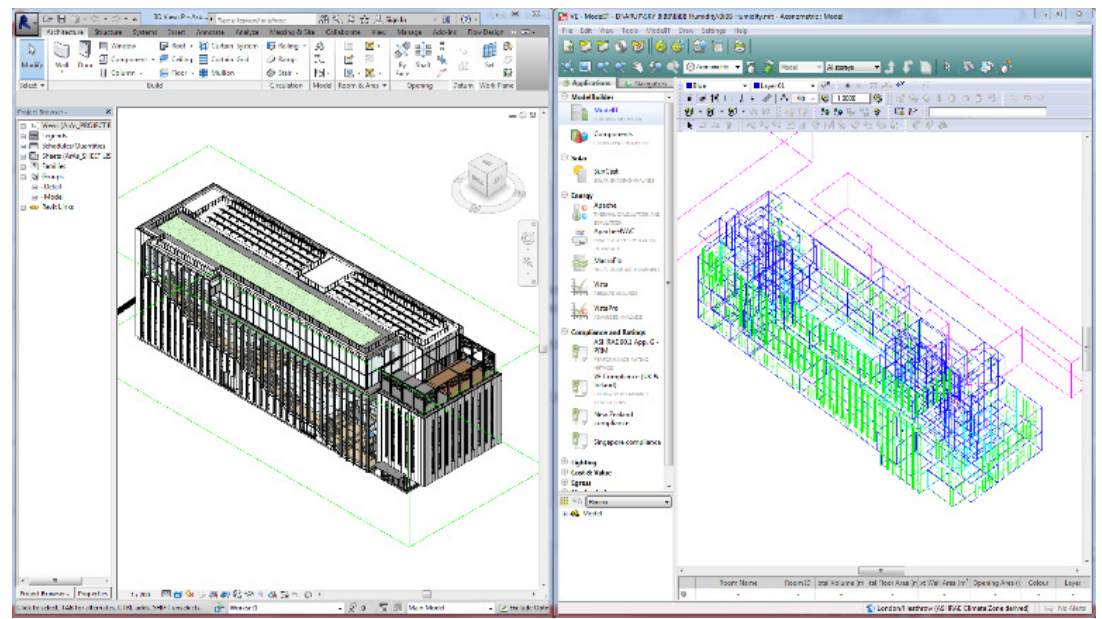

Figure 1: Left: Revit model. Right: IES-VE model (RIBA Stage K).

concept design (RIBA Stage C), technical design (RIBA Stage E) and construction stage (RIBA Stage K) respectively.

However, the model for architectural drawings and the model for energy performance analysis have been built separately. There was no attempt to use the Revit model for the building performance analyses in IES-VE in the early design stages as it was not initially planned by the project team or required by the client side. In order to investigate whether or not something like this is feasible, the output of Stage K Revit model in gbXML format was used as an input file for IESVE simulations. The following text summarised main problems experienced.

\subsection{Building zoning}

The building zoning approaches for BIM and BPA models are different. While the architectural zoning for BIM model is defined by individual interior spaces socalled geometrical zones, BPA has a concept of a thermal zone which is a single space or group of indoor spaces that has uniform thermal load profiles and conditioning requirements [20]. In some cases several geometrical zones form one thermal zone and in some other cases like in atrium spaces, one geometrical zone consists of more than one thermal zone.

There are mainly two different thermal zoning approaches for BPA: zone-based modelling and space-based modelling [20] which could result in some significant difference in analysis results [26]. The zone-based modelling approach is a simplified method which the thermal zones are manually created by the modellers. ASHRAE Standard 90.1 Appendix G, as a typical example, states that the floor plan should be divided into a "core" and "perimeter" zone and the perimeter should be subdivided by orientation. The leftover region in the center of the floor plate forms the "core" [26]. This is useful for creating thermal zones when the actual HVAC design has not been determined, in particular during early design which is equivalent to RIBA Stage C and D. 
The space-based modelling approach, on the other hand, the thermal zoning is defined by individual interior spaces and typically such approach is available later in the design process. When the case study model created in Revit is converted to IES-VE, it is not able to apply the zone-based modelling approach. Only the spacebased modelling approach is available as IES-VE recognises each space as an individual thermal zone [20].

When the case study building model has been imported to IES-VE, there were two types of undefined zones found which the attributes need to be manually assigned in IES-VE. An undefined cavity in the middle of a building resulted in the adjacent interior wall being considered as exterior (Figure 2). This caused the building analysis tool to erroneously assign an exterior wall construction type to it, invalidating the simulation results. When spaces contain suspended ceilings and the resulting plenum areas, spaces must be made for both the room space and the plenum space. However, this spaces normally are not assigned as room spaces in Revit, therefore manual modelling is required in Revit or in IES-VE to consider the thermal effects of the plenum areas.

Architectural Zoning

Thermal Zoning

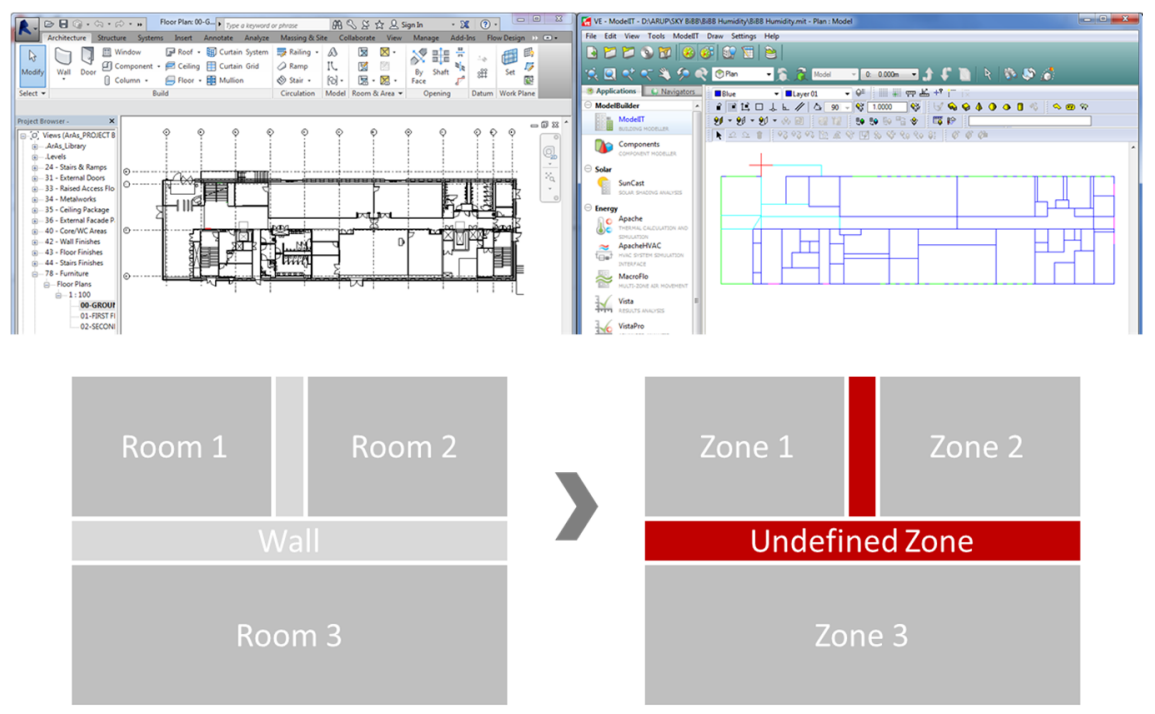

Figure 2: Architectural zoning vs. thermal zoning.

One physical space in the Revit model may contain several areas that are treated individually in the standard spatial program. IES-VE does not recognise the virtual nature of a room separation line. When imported, room separation lines are interpreted as opaque walls. This interpretation also resulted in erroneous simulation results. It is evident that space boundaries form a critical concept for correctly defining appropriate relationships between spaces and the building elements that enclose a space and defining the geometry associated with the spaces independent from the geometry of the bounding elements. 


\subsection{Data format and LoD}

IES has included a number of features in the import function to allow for the gbXML and IFC import from other software. Users can export model directly via the export option in Revit or via the IES-VE Revit Plug-in installed. The IES-VE Revit Plug-in provides a link between Autodesk Revit and IES-VE. The gbXML complexity has its own definition of LoDs when it translates a Revit model to IESVE. There are five levels of complexity for export as seen in the Table 1. The gbXML files was exported from Revit with two different complexities, Simple and Complex With Mullions And Shading Surfaces.

Table 1: gbXML complexity.

\begin{tabular}{|c|c|}
\hline Export type & Brief explanation \\
\hline Simple & $\begin{array}{l}\text { Simple means that Curtain Walls and Curtain Systems are } \\
\text { exported with one complete opening with the total opening area } \\
\text { equal to all openings combined; a curtain wall with } 50 \text { panels gets } \\
\text { exported as } 1 \text { opening. }\end{array}$ \\
\hline $\begin{array}{l}\text { Simple With } \\
\text { Shading Surfaces }\end{array}$ & Export with simple type and shading surfaces. \\
\hline Complex & $\begin{array}{l}\text { Complex means that Curtain Walls and Curtain Systems are } \\
\text { exported with several openings, panel by panel; a curtain wall } \\
\text { with } 50 \text { panels gets exported as } 50 \text { openings. }\end{array}$ \\
\hline $\begin{array}{l}\text { Complex With } \\
\text { Shading Surfaces }\end{array}$ & Export with complex type and shading surfaces. \\
\hline $\begin{array}{l}\text { Complex With } \\
\text { Mullions And } \\
\text { Shading Surfaces }\end{array}$ & $\begin{array}{l}\text { Export with complex type, shading surfaces and mullion. With } \\
\text { Mullions mean that Mullions in Curtain Walls and Systems are } \\
\text { exported as shading surfaces. A "simplified" analytical shading } \\
\text { surface is produced from a mullion based on its centerline, } \\
\text { thickness and offset. }\end{array}$ \\
\hline
\end{tabular}

The model exported with Simple complexity only contains envelopes for each room missing all undefined zones between the rooms when it is imported to IESVE. The model exported with Complex With Mullions And Shading Surfaces complexity contains most of geometry elements except undefined zones between the rooms when it is imported to IES-VE.

Simply by looking at IES-VE model created after importing gbXML files in both complexity levels, it was evident that glazing attributes were not successfully transferred - some glazing parts were not exported as transparent. For both cases, without reference to the level of complexity however, there are a number of error messages which pointed out the room-tags outside rooms, undefined rooms and space boundary setting in Revit model. 


\subsection{Information requirement}

The gbXML format provides functionality to exchange simplified building geometry and some limited HVAC information, therefore it needs to be extended to allow data exchange of complete HVAC definitions and schedules. The IFC model intentionally contains more thorough definitions across all disciplines and life-cycle phases. These definitions, however, need to be implemented in software applications and thoroughly tested for a reliable data exchange as they do not currently support all building information required for BPA. Types of information that currently are not readily available for export through major BIM authoring software include various types of scheduling information (e.g. occupancy, lighting, and equipment), load data and operational characteristics [20].

In addition to the discussion to already presented arguments about a number of errors found from the geometry translation, it is found that the information of the Stage K Revit model cannot be translated to the information required for building performance analysis in IES-VE as listed in Table 2.

Table 2: Information required for IES-VE/exported from Revit.

\begin{tabular}{|c|c|}
\hline Information required for IES-VE & Information exported from Revit \\
\hline Geometric data & $\begin{array}{c}\text { Geometric model is transferrable except } \\
\text { undefined zones. }\end{array}$ \\
\hline Weather data & $\begin{array}{l}\text { Weather data is based on location } \\
\text { information. }\end{array}$ \\
\hline Building type & Building type can be selected. \\
\hline $\begin{array}{l}\text { Construction/material data } \\
\text { (Exterior walls/interior walls, slabs/ } \\
\text { roofs/floors, doors/windows/skylights) }\end{array}$ & $\begin{array}{l}\text { IES-VE does not import construction/ } \\
\text { material data although Revit exports it. }\end{array}$ \\
\hline $\begin{array}{c}\text { Mechanical data } \\
\text { (HVAC equipment, lighting, occupants } \\
\text { and equipment loads, etc.) }\end{array}$ & $\begin{array}{l}\text { IES-VE does not import mechanical data as } \\
\text { mechanical data is limited to be exported } \\
\text { from Revit. }\end{array}$ \\
\hline $\begin{array}{c}\text { Spatial data } \\
\text { (Thermal zoning, operation schedule, } \\
\text { design condition, etc.) }\end{array}$ & $\begin{array}{l}\text { Revit exports spatial data, however } \\
\text { mechanical data is limited to be exported } \\
\text { from Revit. }\end{array}$ \\
\hline
\end{tabular}

The information required for BPA also need to be created with a certain level of detail/development (LoD) considering its uses for BPA as not all relevant information needed for simulations is stored within BIM models and complex shapes can be difficult to remodel. BIM tools limit interoperability for use in energy simulations without appropriate definition of LoDs. 


\section{Conclusion and further recommendations}

When the RIBA Stage K Revit model generated with lack of early consideration for interoperation with BPA tool is used, the model can hardly be converted to BPA tool as due to the following limitations:

- Due to the technical limitations of the tools, Revit does not provide all information required for the analysis using IES-VE. There is no information exchangeable other than the geometry which is not even fully exchanged. IESVE itself also does not have well defined information requirements.

- Errors and data loss are found during the information exchange process even for converting the geometry as the LoD of the architectural model generated by Revit in Stage $\mathrm{K}$ is too complex to control in IES-VE.

In considering the challenges associated with the interoperability between BIM and BPA, it is concluded that it is necessary to develop a shared manual document referred to as 'Information Delivery Manual (IDM)' that clearly outlines the following:

- The scope of the energy modelling activities to meet the project's goals including all the relevant energy modelling inputs, assumptions, and results;

- A listing of all project team members involved, including specification of which team members will perform energy modelling, who will be responsible for providing required inputs to the energy simulations;

- The types and data format of information required for BPA;

- When the information transfers need to occur; and

- An appropriate BIM level of detail/development (LoD 100-500, for example) at each design stage.

The IDM can be applied for each design stage to guide information exchange required for BPA using BIM that can bring improvement in BIM implementation engaged from the early design stages considering building energy performance. The suggested approach will have a potential to make a contribution to advanced BIM implementation for building sustainability as one of the various uses of BIM in practice and encouraging early stage engagement of building performance analysis using BIM.

\section{References}

[1] Intergovernmental Panel on Climate Change (IPCC), "IPCC Fifth Assessment Report (AR5): Climate Change 2014," Cambridge, United Kingdom \& New York, NY, USA, 2014.

[2] United Nations Environment Programme (UNEP), "Buildings and Climate Change: Summary for Decision-Makers," Milan, 2009.

[3] National Institute of Building Sciences (NIBS), "Sustainable | Whole Building Design Guide," 2013. (Online). Available: http://www.wbdg.org/ design/sustainable.php. (Accessed: 01-Jul-2014). 
[4] US Green Building Council (USGBC), Green Associate Study Guide. Washington DC, 2009.

[5] ASHRAE, "Advanced Energy Design Guide for Small to Medium Office Buildings," Atlanta, GA, 2011.

[6] American Institute of Architects (AIA), "Integrated Project Delivery: A Guide," Washington DC, 2007.

[7] Royal Institute of British Architects (RIBA), RIBA Plan of Work 2013 Overview. London: RIBA Publishing, 2013.

[8] HM Government (HMG), "Low Carbon Construction - Innovation \& Growth Team," London, 2010.

[9] McGraw Hill Construction, "Building Information Modeling (BIM): Transforming Design and Construction to Achieve Greater Industry Productivity," New York, NY, 2008.

[10] Institute for BIM in Canada (IBC), "Environmental Scan of BIM Tools and Standards," Ottawa, Ontario, 2011.

[11] P. E. Moakher and S. S. Pimplikar, "Building Information Modeling (BIM) and Sustainability - Using Design Technology in Energy Efficient Modeling," IOSR J. Mech. Civ. Engineering, vol. 1, no. 2, pp. 10-21, 2012.

[12] R. K. Yin, Case study research: design and methods, 4th ed., vol. 5. Thousand Oaks, Calif. ; London: Sage Publications, Inc., 2009.

[13] Colorado Governor's Energy Office (CGEO), "Energy Modeling: A Guide for the Building Professional," 2011.

[14] US Department of Energy (USDOE), "Building Energy Software Tools Directory: Tools by Subject - Whole Building Analysis: Energy Simulation," 2014. (Online). Available: http://apps1.eere.energy.gov/ buildings/tools_directory/subjects.cfm/pagename=subjects/pagename menu=whole building analysis/pagename submenu=energy simulation. (Accessed: 24-Nov-2014).

[15] T. Maile, M. Fischer, and V. Bazjanac, "Building Energy Performance Simulation Tools - a Life-Cycle and Interoperable Perspective," 2007.

[16] T. Catalina, J. Virgone, and E. Blanco, "Development and validation of regression models to predict monthly heating demand for residential buildings," Energy Build., vol. 40, no. 10, pp. 1825-1832, Jan. 2008.

[17] S. Korkmaz, J. I. Messner, D. R. Riley, and C. Magent, "High-Performance Green Building Design Process Modeling and Integrated Use of Visualization Tools," J. Archit. Eng., vol. 16, no. 1, pp. 37-45, Mar. 2010.

[18] H. Kim and K. Anderson, "Energy Modeling System Using Building Information Modeling Open Standards," J. Comput. Civ. Eng., vol. 27, no. 3, pp. 203-211, May 2013.

[19] Zero Carbon Hub, “Closing the Gap Between," London, 2014.

[20] US General Services Administration (USGSA), "GSA Building Information Modeling Guide Series 05 - Energy Performance," Washington DC, 2009.

[21] V. Bazjanac, "IFC BIM-Based Methodology for Semi-Automated Building Energy Performance Simulation,” Berkeley, CA, 2008. 
[22] B. Welle, J. Haymaker, and Z. Rogers, "ThermalOpt: A Methodology for Automated BIM-Based Multidisciplinary Thermal Simulation for Use in Optimization Environments," Stanford, CA, 2011.

[23] R. M. Rossi, D. Brown, B. Park, and R. Boser, "The Integrated Design Process on Paper and In Practice : A Case Study," in Associated Schools of Construction Proceedings of the 46th Annual International Conference, 2010.

[24] F. Leite, A. Akcamete, B. Akinci, G. Atasoy, and S. Kiziltas, "Analysis of modeling effort and impact of different levels of detail in building information models," Autom. Constr., vol. 20, no. 5, pp. 601-609, Aug. 2011.

[25] R. Volk, J. Stengel, and F. Schultmann, "Building Information Modeling (BIM) for existing buildings - Literature review and future needs," Autom. Constr., vol. 38, pp. 109-127, Mar. 2014.

[26] ASHRAE, ASHRAE Standard 90.1-2007 Supplement: Energy Standard for Buildings Except Low-Rise Residential Buildings. Atlanta, GA, 2007. 